\title{
Cost-effectiveness of novel vaccines for tuberculosis control: a decision analysis study
}

\author{
Chia-Lin Tseng ${ }^{1,2}$, Olivia Oxlade ${ }^{1,3}$, Dick Menzies ${ }^{1,3,4}$, Anne Aspler $^{5}$, Kevin Schwartzman ${ }^{1,4^{*}}$
}

\begin{abstract}
Background: The development of a successful new tuberculosis (TB) vaccine would circumvent many limitations of current diagnostic and treatment practices. However, vaccine development is complex and costly. We aimed to assess the potential cost effectiveness of novel vaccines for TB control in a sub-Saharan African country - Zambia relative to the existing strategy of directly observed treatment, short course (DOTS) and current level of bacille Calmette-Guérin (BCG) vaccination coverage.

Methods: We conducted a decision analysis model-based simulation from the societal perspective, with a 3\% discount rate and all costs expressed in 2007 US dollars. Health outcomes and costs were projected over a 30-year period, for persons born in Zambia (population 11,478,000 in 2005) in year 1. Initial development costs for single vaccination and prime-boost strategies were prorated to the Zambian share $(0.398 \%)$ of global BCG vaccine coverage for newborns. Main outcome measures were TB-related morbidity, mortality, and costs over a range of potential scenarios for vaccine efficacy.
\end{abstract}

Results: Relative to the status quo strategy, a BCG replacement vaccine administered at birth, with $70 \%$ efficacy in preventing rapid progression to TB disease after initial infection, is estimated to avert 932 TB cases and 422 TBrelated deaths (prevention of 199 cases/100,000 vaccinated, and 90 deaths/100,000 vaccinated). This would result in estimated net savings of $\$ 3.6$ million over 30 years for 468,073 Zambians born in year 1 of the simulation. The addition of a booster at age 10 results in estimated savings of $\$ 5.6$ million compared to the status quo, averting 1,863 TB cases and 1,011 TB-related deaths (prevention of 398 cases/100,000 vaccinated, and of 216 deaths/100,000 vaccinated). With vaccination at birth alone, net savings would be realized within 1 year, whereas the prime-boost strategy would require an additional 5 years to realize savings, reflecting a greater initial development cost.

Conclusions: Investment in an improved TB vaccine is predicted to result in considerable cost savings, as well as a reduction in TB morbidity and TB-related mortality, when added to existing control strategies. For a vaccine with waning efficacy, a prime-boost strategy is more cost-effective in the long term.

\section{Background}

Nearly a third of the world's population harbors the Mycobacterium tuberculosis bacillus, and about 1.7 million people die of tuberculosis (TB) each year [1]. Since the early 1990s, inconsistent treatment and the consequent emergence of drug resistance, and widespread HIV infection have contributed to the global epidemic. Other major challenges include limited diagnostic tools, and suboptimal provider/patient adherence with recommended diagnostic and treatment interventions [2]. The

\footnotetext{
* Correspondence: kevin.schwartzman@mcgill.ca

${ }^{1}$ Respiratory Epidemiology and Clinical Research Unit, Montreal Chest Institute, Montreal, Canada

Full list of author information is available at the end of the article
}

World Health Organization's recommended strategy of directly observed treatment, short course (DOTS) has reduced incidence in most world regions; however, TB control in sub-Saharan Africa and in the former Soviet Union continues to be a particular concern $[3,4]$. In response to these challenges, the World Health Organization (WHO) has broadened its approach to TB control, for example by considering HIV-TB co-infection, smear-negative $\mathrm{TB}$ and treatment for latent infection [5]. In addition, there is intensive research into novel diagnostic, therapeutic, and preventive interventions. The development of an effective $\mathrm{TB}$ vaccine holds great appeal; by preventing TB infection and/or disease, it

\section{Biomed Central}


would circumvent limitations of current diagnostic and treatment strategies.

The only currently licensed TB vaccine, bacille Calmette-Guérin (BCG), has proven at least modestly efficacious in preventing tuberculous meningitis and disseminated disease in young children, although estimates of protection vary [6,7]. It has very limited efficacy in preventing adult pulmonary disease, the form of disease that is contagious, and hence fuels the continuing epidemic. Based on current development timelines, next-generation $\mathrm{TB}$ vaccines may become available in the next $5-7$ years $[8,9]$. Because a suboptimal vaccine is already in widespread use, an improved vaccine is likely to attain the same or even better population coverage. However, costs for development, testing, and implementation may be substantial. Given the limited resources available for TB control, it is relevant to consider likely costs and public health benefits of a novel vaccine, based on currently available information. If vaccine development is likely to prove very expensive, with public health benefits accruing only in the distant future, then other interventions may be accorded higher priority.

Using a simulation model, we aimed to predict health outcomes and costs with different scenarios for the introduction of a novel TB vaccine in a sub-Saharan African country. We were particularly interested in the impact of varying scenarios for vaccine efficacy, and for the mechanism and timing of vaccine effect. As a case study, we estimated TB-related morbidity, mortality, and costs of a novel TB vaccine introduced in Zambia, a country with high HIV prevalence (9.4\%) and very high annual TB incidence (247 smear positive cases/100,000) $[1,10]$. We projected changes in TB morbidity, mortality, and cost when an improved vaccine replaces the current BCG vaccination program, and supplements the current DOTS program, over a range of scenarios for vaccine efficacy.

\section{Methods}

\section{General description of the model}

We developed a decision analysis model, incorporating multiple Markov processes, using TreeAge Pro Suite 2007 (TreeAge Software, Williamstown, MA). The model estimated the probability of developing active TB disease, TB mortality, and associated costs over a period of 30 years for the existing TB control strategy (BCG for newborns, plus DOTS based on smear diagnosis and standard drug regimens), and for two alternative country wide vaccination strategies. We simulated a hypothetical fixed cohort of newborns who joined the existing population of Zambia. The characteristics of the Zambian population used for this simulation are summarized in Table 1 . The analysis was conducted from a societal perspective, including both direct and indirect costs. All future expenditures and outcomes were discounted at a rate of $3 \%$ annually [11].

For the purpose of the primary analysis, current epidemiologic and tuberculosis control parameters (Table 1) were assumed to remain constant over the simulation period: annual risk of TB infection, DOTS coverage, case detection rate, treatment outcomes, smear-positive incidence, HIV seroprevalence, and prevalence of initial TB drug resistance. The status quo included the protective effects of existing BCG vaccination, at the current level of vaccine coverage and with a presumed $50 \%$ reduction in the risk of primary progression to pulmonary disease, tuberculous meningitis or disseminated disease during early childhood $[12,13]$. The reduction in risk conferred by existing BCG vaccination is assumed to apply for a total duration of 10 years, but its protective effect is assumed to wane linearly to zero over this period of time.

In primary analysis, the vaccination strategies that we compared with the existing TB control program were, 1) vaccination with a novel $T B$ vaccine at birth, and 2) vaccination with a novel vaccine at birth plus a booster dose at age 10. Both comparison strategies were assumed to cover the same proportion of the target population as the current BCG program. The protective effect of all vaccine doses was assumed to be immediate, and would then wane linearly to zero over a period of 10 years. In the primary analysis, the replacement TB vaccine for neonates was assumed to have an initial efficacy of $70 \%$ for preventing rapid progression to TB disease. Hence the replacement vaccine would work similarly to BCG, but with greater efficacy. As a result, the incidence of contagious smear-positive pulmonary disease will remain largely constant during the first years after introduction of the novel vaccine. This is because young children develop primary, disseminated and/or meningeal forms of the disease which are rarely contagious.

The booster dose administered at the age of 10 was also assumed to be $70 \%$ efficacious, and to work by preventing rapid progression to active disease. Hence it would only be of benefit to persons who had not yet acquired latent TB infection by age 10 .

Other potential mechanisms for vaccine action could be to reduce: 1) acquisition of initial infection following exposure to Mycobacterium tuberculosis; or 2) late reactivation of longstanding latent TB infection. These alternate mechanisms of vaccine action, and their impact on health outcomes and costs, were considered in sensitivity analyses. For this reason, the time frame of all analyses was 30 years, so that potential benefits related to protection against acquiring TB infection and to prevention of late reactivation could be tracked into early 
Table 1 Epidemiologic and Program Data for Zambia

\begin{tabular}{|c|c|c|}
\hline Variable & Value & Source \\
\hline Population (2005) & $11,478,000$ & [56] \\
\hline Live births/1,000 population (2007) & 40.78 & [57] \\
\hline Live births per year & 468,073 & Calculated from $[56,57]$ \\
\hline Percent of global BCG vaccine coverage & $0.398 \%$ & [34] \\
\hline Percent of target population vaccinated with $B C G$ & $92 \%$ & [34] \\
\hline Gross National Income per capita (US\$) 2005 & $\$ 500$ & [58] \\
\hline Life expectancy at birth (years) & 38.4 & [58] \\
\hline All cause mortality & Age specific & [59] \\
\hline New estimated TB smear-positive incidence per 100,000 (2005) & 247 & {$[1]$} \\
\hline Annual risk of TB infection (ARI) & $4.94 \%$ & Calculated from $[1,16]$ \\
\hline Probability of being diagnosed and treated for LTBI & $1 \%$ & {$[20]^{*}$} \\
\hline Completion of LTBI treatment & $67 \%$ & [21] \\
\hline HIV prevalence (2006) & $9.4 \%$ & [10] \\
\hline HIV incidence per annum & $0.96 \%$ & Calculated from [22] \\
\hline DOTS coverage (2005) & $100 \%$ & {$[1]$} \\
\hline DOTS case detection rate (2005) & $52 \%$ & [1] \\
\hline \multicolumn{3}{|l|}{ Initial drug resistance } \\
\hline Single drug resistance & $8.5 \%$ & {$[60]$} \\
\hline Multi drug resistancet & $1.8 \%$ & [61] \\
\hline \multicolumn{3}{|l|}{ DOTS new case treatment outcomes (2005) } \\
\hline Cure/complete & $83 \%$ & \\
\hline Default/transfer/not evaluated & $8 \%$ & \\
\hline Die & $8 \%$ & \\
\hline Fail & $1 \%$ & \\
\hline DOTS re-treatment outcomes (2005) & & {$[1]$} \\
\hline Cure/complete & $78 \%$ & \\
\hline Default/transfer/not evaluated & $7 \%$ & \\
\hline Die & $13 \%$ & \\
\hline Fail & $2 \%$ & \\
\hline
\end{tabular}

*This assumes only dually infected individuals (HIV and TB) whose HIV infection is detected and are tuberculin tested will be treated (based on a Haitian study). tDefined as resistance to isoniazid and rifampin, with or without other drug resistance.

adulthood. However, for the primary analysis we also compared outcomes at 5,10 , and 20 years.

Preliminary data suggest some novel TB vaccines currently under development will be safer than BCG for administration to HIV-positive individuals [8,9]. The model assumed all vaccines to have similar protective efficacy in individuals with early HIV infection to that in seronegative persons. We assumed that the vaccine had no effect on the development of active TB in persons with clinical AIDS, based on severe impairment of cell-mediated immunity. To the extent that this could underestimate vaccine benefit, this was a conservative assumption.

Model health states, transitions, and calculations

In the model, TB-related health states, along with key pathogenetic assumptions corresponding to Markov state transition probabilities (e.g. risk of acquiring tuberculosis infection, subsequent risk of active TB) were as previously described $[14,15]$, modified and extended to include vaccination (Table 2).

Model cohort members were classified into five broad TB-related health states: 1) uninfected; 2) latent tuberculosis infection (LTBI); 3) active tuberculosis; 4) successfully treated, or spontaneously resolved active TB; and 5) chronic TB (MDR-TB). Latent TB, active TB, and spontaneously resolved active TB were further subdivided into three categories based on drug sensitivity: drug sensitive, single-drug resistant, or multi-drug resistant. The annual risk of infection was calculated from the estimated incidence of smear-positive cases using the Styblo formula [16]. We estimated that a new TB infection would progress to active disease in $5 \%$ of HIVnegative individuals within 2 years of acquiring the infection [17], and long-standing LTBI would re-activate at an annual rate of $0.1 \%$ thereafter in HIV-negative 
Table 2 Model Pathogenetic Variables and Assumptions

\begin{tabular}{|c|c|c|}
\hline Variable & Value & Source \\
\hline \multicolumn{3}{|l|}{ HIV Infection } \\
\hline Annual risk of progression - asymptomatic to AIDS & $7 \%$ & {$[22,62]$} \\
\hline Annual risk of death - early HIV (asymptomatic) & $4.6 \%$ & [22] \\
\hline Annual risk of death - clinical AIDS & $22 \%$ & [22] \\
\hline Median survival with early HIV & $9.8 \mathrm{yrs}$ & {$[22,62]$} \\
\hline Median survival with clinical AIDS & 9 months & [22] \\
\hline \multicolumn{3}{|l|}{ Risk of developing active TB disease } \\
\hline \multicolumn{3}{|l|}{ HIV uninfected } \\
\hline Within 2 years of new TB infection & $5 \%$ & {$[17,63]$} \\
\hline Within 2 years of re-infection after cured TB disease & $1 \%$ & {$[64,65]$} \\
\hline Late re-activation from longstanding latent $\mathrm{TB}^{*}$ & $0.1 \% /$ year & {$[18,19]$} \\
\hline \multicolumn{3}{|l|}{ Early HIV } \\
\hline Within 2 years of new TB infection & $33 \%$ & Extrapolated \\
\hline Within 2 years of re-infection after cured TB disease & $33 \%$ & Assumption \\
\hline Late re-activation from longstanding latent $\mathrm{TB}^{*}$ & 3.4\%/year & {$[23,66,67]$} \\
\hline \multicolumn{3}{|l|}{ Clinical AIDS } \\
\hline Within 2 years of new TB infection & $100 \%$ & {$[25,68-71]$} \\
\hline Within 2 years of re-infection after cured TB disease & $100 \%$ & Assumption \\
\hline Late re-activation from longstanding latent $\mathrm{TB}^{*}$ & $33 \% /$ year & [23] \\
\hline \multicolumn{3}{|l|}{ Untreated Smear Positive TB Outcomes (HIV-negative) } \\
\hline Spontaneous resolution & $25 \%$ & [72] \\
\hline Relapse after spontaneous resolution & $2.5 \% /$ year & {$[72,73]$} \\
\hline Mortality rate within 2 years & $33 \%$ at 1 year; $50 \%$ at 2 years & [74] \\
\hline \multicolumn{3}{|l|}{ Untreated Smear Positive TB Outcomes (HIV-positive) } \\
\hline Spontaneous resolution & $0 \%$ & Assumption \\
\hline Mortality rate within 2 years & $100 \%$ & Assumption \\
\hline \multicolumn{3}{|l|}{ Treated Smear Positive TB Outcomes (HIV-negative) } \\
\hline Relapse after cure (total over next 2 years) & $3.0 \%$ & [75-79] \\
\hline Cure rate if default (single drug resistant or drug sensitive) $)^{* *}$ & $62.4 \%$ & [80-83] \\
\hline \multicolumn{3}{|l|}{ Effect of Drug Sensitivity on Treatment Outcomes } \\
\hline Relative risk of treatment failure - single drug resistant & 2.0 & [84] \\
\hline Relative risk of treatment failure - multi-drug resistant & 10.5 & [84] \\
\hline Relative risk of death - single drug resistant & 1.0 & [84] \\
\hline Relative risk of death - multi-drug resistant & 4.5 & [84] \\
\hline \multicolumn{3}{|l|}{ Multi-Drug Resistant TB Treatment Outcomes } \\
\hline Completed/Cured & $68.6 \%$ & [85] \\
\hline Default/Failed/Transferred & $17.1 \%$ & [85] \\
\hline Died & $14.2 \%$ & [85] \\
\hline \multicolumn{3}{|l|}{ Treated Smear Positive TB Outcomes (HIV-positive) } \\
\hline Relative risk of death during TB treatment with HIV infection & 2.25 & {$[24,26,86,87]$} \\
\hline Relapse after successful TB treatment (cured) & $3.1 \%$ & {$[88-90]$} \\
\hline
\end{tabular}

* Assumes rate of reactivation beyond 2 years after TB infection is the same whether it is after a first infection or after re-infection.

** Transfer out considered equivalent to default [91]. Overall cure rate if default based on timing of default [73], and cure rates from trials of very short course treatment [81-83].

individuals $[18,19]$. To date, control strategies in lowand middle- income countries have focused largely on active cases, with limited treatment of latent infection [5]. We therefore assumed that the only persons treated for latent TB infection would be individuals diagnosed with concurrent HIV-latent TB infection (the latter based on tuberculin test results) [20]. Of those treated, we estimated only $67 \%$ would complete treatment for latent infection [21].

HIV-related health states were divided into uninfected, early HIV (asymptomatic), and late HIV (clinical AIDS). The annual risk of HIV infection was estimated to be 
$0.96 \%$, calculated from the adult population prevalence of HIV in Zambia divided by the mean survival with HIV infection in a low-income setting [10,22]. The risks of TB progression, re-activation, relapse, and mortality were assumed to be much higher in HIV-positive individuals [23-26]. These and other key pathogenetic assumptions with respect to TB and HIV acquisition, progression, and clinical outcomes are listed in Table 2.

Beginning from the first year, we estimated the proportion of the cohort developing active $\mathrm{TB}$, dying from $\mathrm{TB}$, dying from HIV, and dying from all other causes. In each year, costs associated with each branch of the decision tree were determined and accumulated. Cohort members surviving each year entered the subsequent year of the simulation, starting in the health state determined by events of the preceding year. Final outcomes including costs were multiplied by the size of the newborn population to generate expected values over the 30-year simulation, for the cohort of newborns born in Year 1. A simplified schematic of the decision tree is shown in Figure 1.

\section{Costs}

Costs, expressed in 2007 U.S. dollars, were estimated from a societal perspective. Direct costs included those borne by the government and the healthcare system, plus costs for implementation and maintenance. Indirect costs included out-of-pocket expenditures by patients and families, and lost productivity due to TB related disability and death. For children with TB, indirect costs reflected costs borne by their families, namely family members taking time off work and/or paying out-ofpocket costs related to children's illness and care. A summary of direct and indirect costs per patient managed in Zambia is shown in Table 3.
Data regarding the number of health care visits and out-of-pocket expenditures for patients and families in the pre-diagnostic, hospitalization, treatment, and follow-up phases were collected and analyzed from a previous survey of adult TB patients in Zambian urban primary health care centres [27]. As we did not have directly gathered data for costs to the Zambian health care system, health care system costs were estimated from a survey of Haitian TB care providers [15], where the annual gross national income (GNI) per capita at the time of the study in 2003 was similar to that of Zambia now. Lost income due to TB-related medical visits and TB-related premature death were determined by the model based on GNI per capita, the number of remaining years in the simulation, and the presence or absence of HIV infection. The median length of survival for HIV-infected persons was estimated to be 9.8 years with early HIV and 9 months with clinical AIDS [22]. For adults with active TB. disability costs were calculated based on an assumed 50\% reduction in productivity from symptom onset until diagnosis, and during the first 2 months of treatment [28-30]. Untreated patients or patients who failed treatment had a $50 \%$ reduction in productivity for the duration of their illness.

Costs for the maintenance of the DOTS program were based on detailed evaluations of DOTS implementation in Ecuador [31], adjusted for gross national income per capita in Zambia and converted to 2007 dollars using the consumer price index [32]. Costs of anti-tuberculosis drugs for active and latent TB were as listed by the Global Drug Facility [33].

Initial research, development, and production costs for single vaccination and prime-boost strategies were projected to be $\$ 141$ million and $\$ 194$ million respectively, and prorated to the Zambian share $(0.4 \%)$ of global

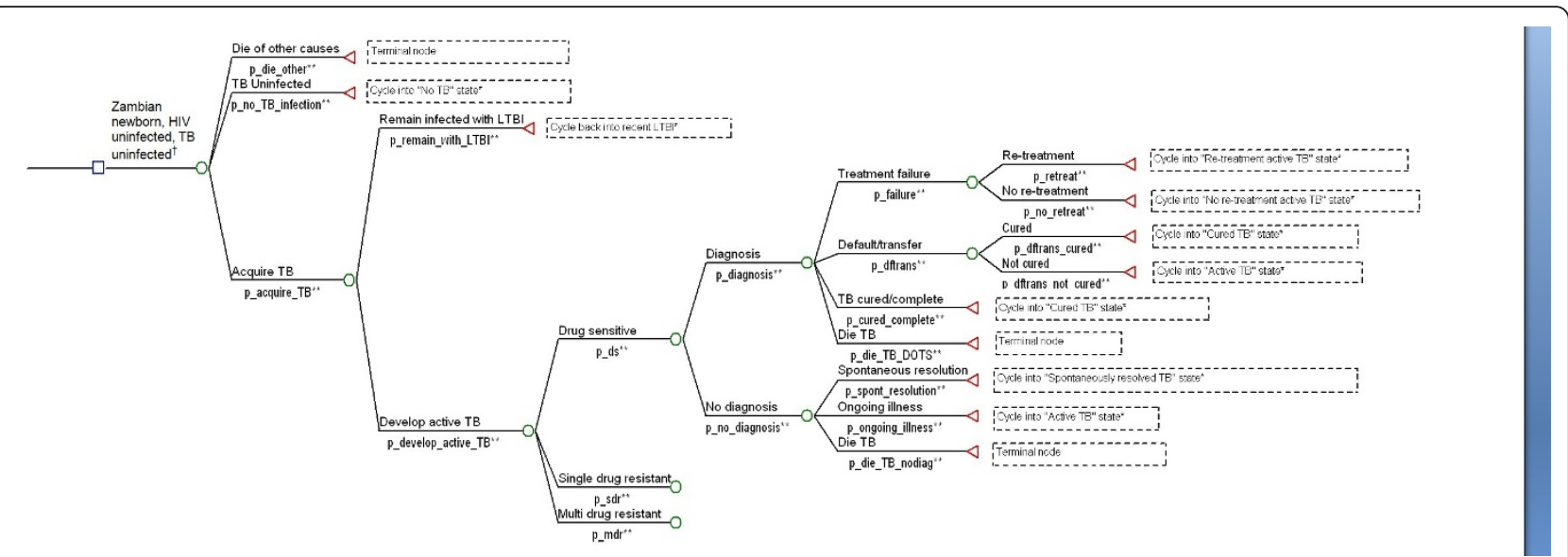

Figure 1 Sample decision analysis tree for Zambian newborn initially without HIV or TB infection. Footnotes: * States entered in subsequent cycles not shown in this figure ** The letter " $p$ " preceding a variable name denotes probability † Decision tree structure for HIV infection not shown in this figure. 
Table 3 Direct and indirect costs per tuberculosis patient managed in Zambia

\begin{tabular}{|c|c|c|}
\hline Type of Cost & Mean & Source \\
\hline \multicolumn{3}{|l|}{ Pre-Diagnosis } \\
\hline Number of medical visits & 1.94 & $\mathrm{ZCQ}^{\dagger}$ \\
\hline Lab costs (3 AFB smears) & $\$ 8.49$ & [92] \\
\hline Patient out-of-pocket expenditures for visits & $\$ 10.63$ & $\mathrm{ZCQ}^{\dagger}$ \\
\hline Indirect Lost income for patient/family for visits* & $\$ 1.47$ & $\mathrm{ZCQ}^{\dagger}$ \\
\hline \multicolumn{3}{|l|}{ Post-Diagnosis } \\
\hline Hospitalisation Number of hospital days & 7.13 & $\mathrm{ZCQ}^{\dagger}$ \\
\hline Direct Health system costs for hospital days & $\$ 98.68$ & $\mathrm{HCQ}^{\ddagger}$ \\
\hline Patient out-of-pocket expenditures: hospital days & $\$ 128.91$ & $\mathrm{ZCQ}^{\dagger}$ \\
\hline Indirect Lost income for patient/family for hospital days* & $\$ 15.61$ & $\mathrm{ZCQ}^{\dagger}$ \\
\hline \multicolumn{3}{|l|}{ Direct Observation of Treatment (DOT) } \\
\hline Number of visits & 108 & $\mathrm{ZCQ}^{\dagger}$ \\
\hline Direct Health system costs for visits & $\$ 78.84$ & $\mathrm{HCQ}^{\ddagger}$ \\
\hline Drug costs (new case) & $\$ 5.37$ & [33] \\
\hline Patient out-of-pocket expenditures for visits & $\$ 15.12$ & $\mathrm{ZCQ}^{\dagger}$ \\
\hline Indirect Lost income for patient/family for visits* & $\$ 51.84$ & $\mathrm{ZCQ}^{\dagger}$ \\
\hline \multicolumn{3}{|l|}{ Follow-up } \\
\hline Number of visits & 7 & $\mathrm{ZCQ}^{\dagger}$ \\
\hline Direct Health system costs for visits & $\$ 27.44$ & $\mathrm{HCQ}^{\ddagger}$ \\
\hline Patient out-of-pocket expenditures for visits & $\$ 0.84$ & $\mathrm{ZCQ}^{\dagger}$ \\
\hline Indirect Lost income for patient/family for visits* & $\$ 4.06$ & $\mathrm{ZCQ}^{\dagger}$ \\
\hline \multicolumn{3}{|l|}{ Disability Costs } \\
\hline Direct Patient miscellaneous direct costs ${ }^{* *}$ & $\$ 2.12$ & $\mathrm{ZCQ}^{\dagger}$ \\
\hline Indirect Lost income due to patient disability" & $\$ 138.10$ & $\mathrm{ZCQ}^{\dagger}, \mathrm{HCQ}^{\ddagger}$ \\
\hline Family miscellaneous indirect costs ${ }^{\text {nी? }}$ & $\$ 46.44$ & $\mathrm{HCQ}^{\dagger}$ \\
\hline \multicolumn{3}{|l|}{ Total Cost per TB patient managed } \\
\hline Direct Health system & $\$ 226.43$ & \\
\hline Patient out-of-pocket and miscellaneous costs & $\$ 157.62$ & \\
\hline Indirect Patient/family lost income and miscellaneous costs & $\$ 257.52$ & \\
\hline Total Health system and patient/family & $\$ 641.57$ & \\
\hline \multicolumn{3}{|l|}{ Vaccination } \\
\hline Initial investment ${ }^{\S}$ - BCG replacement only & $\$ 1.20 /$ vaccinated & {$[7,34,57]$} \\
\hline With booster (total) & $\$ 1.65 /$ vaccinated & {$[7,34,57]$} \\
\hline Unit cost ${ }^{\S \S}-B C G$ & $\$ 2.00$ & [93] \\
\hline BCG replacement only & $\$ 1.10^{\dagger+}$ & [9] \\
\hline With Booster (total) & $\$ 3.40$ & [9] \\
\hline
\end{tabular}

† Values based on Zambian TB Cost Questionnaire 2006 [27].

‡ Values based on Haiti TB Patient Cost Questionnaire [15], where GNI per capita is similar to Zambia.

* Lost income based on average per capita gross national income - \$500 - [58] and average work week of 40 hours.

** Direct patient/family expenditures (while ill with TB disease) that are in addition to money spent while visiting health establishments or hospitals (e.g. cleaning, food supplements, childcare).

I Disability costs based on cure/complete treatment outcome (2 months disability) [28-30].

ๆๆ Based on total hours spent by family members helping patient at home.

$\S$ Initial investment includes research, development, and production costs.

$\S \S$ Unit cost includes distribution, administration, and vaccine dose costs.

†† BCG replacement unit cost estimates provided by Aeras [9] were lower than that of current BCG - likely secondary to improved manufacturing and/or distribution efficiency.

BCG vaccine coverage for newborns [34]. Survey data collected prior to the $36^{\text {th }}$ IUATLD Conference in Paris (2005) provided the basis for all vaccine costs [9], for which the Aeras 403 recombinant BCG (rBCG) was used as the replacement TB vaccine, and the Aeras 402
Crucell Ad35 vector expressing TB antigens was used as the booster. Of note, we assumed no additional infrastructure costs for distribution and delivery of a novel vaccine, as an extensive program for BCG vaccination already exists as part of the WHO Expanded Program 
for Immunization (EPI). We assumed that any HIV screening costs associated with vaccination would be the same as for the current BCG program.

\section{Sensitivity analyses}

We performed extensive sensitivity analyses to test the robustness of the model to a range of parameter values. Key epidemiologic factors such as HIV prevalence and TB infection risk were varied, where available, within published ranges. Assumed costs were doubled and quadrupled to assess their impact on the cost effectiveness of the vaccine strategies. To account for potentially higher discount rates in low-income countries, we considered discount rates ranging from $2-6 \%$. In addition, combinations of unfavorable assumptions were used to describe a "worst case" scenario. Since the first new vaccines are now in the early and middle phases of human clinical trials, there are no definitive efficacy data. Therefore, we examined the effects of varying the assumed efficacy and mechanism of action for the vaccine strategies. We considered prevention of acquisition of initial infection, and prevention of late reactivation as alternate mechanisms for vaccine action.

This study used a hypothetical simulation model based on previously published data, so research ethics committee approval was not required. McGill University, the Fonds de la Recherche en Santé du Québec, and the Canadian Institutes of Health Research provided salary support to the researchers, but had no role in any aspect of this study. All members of the research team had full access to all data and to the decision analysis model.

\section{Results}

With the status quo, the model projected 25,557 active TB cases and 18,379 TB-related deaths over a period of 30 years, among 468,073 Zambians born in Year 1. The associated direct costs were $\$ 11.4$ million and indirect costs were $\$ 45.1$ million. Relative to current TB control measures, a BCG replacement vaccine administered at birth, with $70 \%$ efficacy in preventing rapid progression to TB disease after initial infection, is estimated to prevent 932 active TB cases and 422 TB-related deaths over the same period. This corresponds to a reduction of 199 cases and 90 deaths per 100,000 vaccinated. The prevention of these active TB cases and TB-related deaths would decrease direct costs by $\$ 0.2$ million, and indirect costs by $\$ 3.4$ million, resulting in a net reduction of $\$ 3.6$ million in societal costs. Hence a new vaccine is predicted to result in cost savings as well as reduced morbidity and mortality.

The addition of a booster vaccine dose would avert 1,863 active TB cases and 1,011 TB-related deaths as compared to the status quo-a further reduction of $931 \mathrm{~TB}$ cases and 589 TB-related deaths beyond a single neonatal dose of the new vaccine. However, this would increase total direct costs to $\$ 11.9$ million, reflecting larger investment in research, development, distribution, and vaccine administration. Substantial indirect cost savings of $\$ 6.2$ million however, would produce net societal cost savings of $\$ 5.6$ million compared to the status quo, or $\$ 2.0$ million compared to a single dose of the new vaccine at birth.

Tables 4 and 5 summarize TB related costs, TB morbidity and mortality for each strategy over varying time horizons, for the entire group of newborns (Table 4), and per 100,000 newborns (Table 5). With vaccination at birth alone, net savings for Zambia would begin within 1 year, whereas the prime-boost strategy would require an additional 5 years to realize savings - reflecting greater initial development costs (Figure 2). In the long run ( $>16$ years), the prime-boost vaccination strategy would be the cheapest.

\section{Sensitivity analyses}

Table 6 summarizes sensitivity analyses for key parameters. Net cost savings related to prevention of additional TB cases would be expected even if the initial cost of research and development were quadrupled, or if the vaccine unit cost were quadrupled. If the vaccine's duration of action were halved to 5 years, BCG replacement vaccination at birth alone would produce a total added societal cost of $\$ 0.55$ million, and prevent fewer TB cases than the current BCG vaccine, which had an assumed duration of action of 10 years. However, with the prime-boost vaccination strategy there were predicted societal cost savings even when the vaccine's duration of action was halved.

Savings as well as prevention of morbidity and mortality would increase for both vaccination strategies if the prevalence of HIV were higher, reflecting the effect of concurrent HIV infection on risks of rapid primary TB progression and late TB re-activation. Similarly, if the annual risk of TB infection were higher, cost savings would increase. Conversely, with decreases in HIV prevalence or in the annual risk of TB infection, the number of TB cases prevented by vaccination would decrease. Nonetheless, net cost savings are expected with both vaccine strategies even with a $50 \%$ reduction in HIV prevalence or a $50 \%$ reduction in the annual risk of TB infection. With increases in the annual discount rate, projected cost savings decrease as do TB cases prevented and deaths prevented. Net cost savings are predicted for both vaccine strategies even when the discount rate is doubled, to $6 \%$.

In a "worst case" scenario where three key assumptions were made less favorable (initial development cost doubled, vaccine unit cost doubled, vaccine duration of action halved), both vaccination strategies would be associated with increased societal costs as compared to 
Table 4 Cost and effectiveness of three strategies for tuberculosis control in Zambian newborns over $\mathbf{3 0}$ years, for the total cohort of 468,073 newborns

\begin{tabular}{|c|c|c|c|c|c|c|}
\hline Ranked from least to & $\begin{array}{l}\text { Strategies } \\
\text { most expensive with respect to total cost }\end{array}$ & $\begin{array}{l}\text { Total Costs } \\
\$ \text { million }\end{array}$ & $\begin{array}{l}\text { Direct Costs } \\
\$ \text { million }\end{array}$ & $\begin{array}{l}\text { Indirect Costs } \\
\$ \text { million }\end{array}$ & TB Cases & TB Mortality \\
\hline \multirow[t]{3}{*}{ After 5 years } & Novel TB vaccine at birth & 7.123 & 3.348 & 3.775 & 5,771 & 2,861 \\
\hline & Status quo & 8.154 & 3.539 & 4.615 & 6,643 & 3,215 \\
\hline & Novel TB vaccine at birth with Booster & 8.347 & 4.572 & 3.775 & 5,771 & 2,861 \\
\hline \multirow[t]{3}{*}{ After 10 years } & Novel TB vaccine at birth & 16.702 & 5.721 & 10.981 & 11,608 & 6,452 \\
\hline & Novel TB vaccine at birth with Booster & 17.926 & 6.945 & 10.981 & 11,608 & 6,452 \\
\hline & Status quo & 18.754 & 5.980 & 12.774 & 12,592 & 6,896 \\
\hline \multirow[t]{3}{*}{ After 20 years } & Novel TB vaccine at birth with Booster & 36.486 & 10.129 & 26.357 & 19,388 & 12,772 \\
\hline & Novel TB vaccine at birth & 37.459 & 9.330 & 28.129 & 20,366 & 13,380 \\
\hline & Status quo & 40.463 & 9.583 & 30.880 & 21,305 & 13,808 \\
\hline \multirow[t]{3}{*}{ After 30 years } & Novel TB vaccine at birth with Booster & 50.876 & 11.930 & 38.946 & 23,694 & 17,368 \\
\hline & Novel TB vaccine at birth & 52.863 & 11.126 & 41.737 & 24,625 & 17,957 \\
\hline & Status quo & 56.481 & 11.377 & 45.104 & 25,557 & 18,379 \\
\hline
\end{tabular}

the status quo strategy. For the single BCG replacement dose, 98 more TB cases and 87 more TB deaths would be expected, as well as higher societal costs. For the prime-boost strategy, additional societal costs would then be $\$ 77$ per case prevented, and $\$ 160$ per death averted, as compared to the status quo.

Changing the predicted efficacy and assumed mechanism of action showed that vaccines with efficacy $\geq 60 \%$ and $50 \%$ targeting rapid progression and acquisition of infection respectively, would be cost-saving relative to current conditions (Figures 3 and 4). Due to the low annual risk of re-activation in HIV-negative persons $(0.1 \%)$, the spreading of risk over a lifetime, and loss of partial protection against rapid primary progression conferred by the current BCG vaccine, a vaccine targeting late reactivation alone would be more costly than the status quo, even with 90\% efficacy (Figure 5). Of course, a vaccine that is safe and effective in preventing late reactivation is likely to be widely administered throughout the community (not only to newborns), a scenario that was beyond the scope of the present analysis.

\section{Discussion}

Our comparison of two vaccination strategies with the current DOTS and BCG vaccination strategy for tuberculosis control in Zambia suggest that improved vaccines could reduce TB-related mortality and morbidity, and produce cost savings over a 30-year time horizon. The projections were generally robust in sensitivity analyses, even with assumed protective efficacy of $60 \%$ with a novel vaccine. Not surprisingly, neonatal vaccines which target initial infection or rapid progression will be more cost-effective in the short-term than those which target late re-activation. The current pipeline for novel vaccines predominantly focuses on these mechanisms of action $[8,35]$.

Table 5 Cost and effectiveness of three strategies for tuberculosis control in Zambian newborns over 30 years, per 100,000 newborns

\begin{tabular}{|c|c|c|c|c|c|c|}
\hline \multicolumn{2}{|c|}{ Ranked from least to most expensive with respect to total cost } & $\begin{array}{l}\text { Total Costs } \\
\text { \$million }\end{array}$ & $\begin{array}{l}\text { Direct Costs } \\
\text { \$million }\end{array}$ & $\begin{array}{l}\text { Indirect Costs } \\
\text { \$million }\end{array}$ & TB Cases & TB Mortality \\
\hline \multirow[t]{3}{*}{ After 5 years } & Novel TB vaccine at birth & 1.522 & 0.715 & 0.806 & 1,233 & 611 \\
\hline & Status quo & 1.742 & 0.756 & 0.986 & 1,419 & 687 \\
\hline & Novel TB vaccine at birth with Booster & 1.783 & 0.977 & 0.806 & 1,233 & 611 \\
\hline \multirow[t]{3}{*}{ After 10 years } & Novel TB vaccine at birth & 3.568 & 1.222 & 2.346 & 2,480 & 1,378 \\
\hline & Novel TB vaccine at birth with Booster & 3.830 & 1.484 & 2.346 & 2,480 & 1,378 \\
\hline & Status quo & 4.007 & 1.278 & 2.729 & 2,690 & 1,473 \\
\hline \multirow[t]{3}{*}{ After 20 years } & Novel TB vaccine at birth with Booster & 7.795 & 2.164 & 5.631 & 4,142 & 2,729 \\
\hline & Novel TB vaccine at birth & 8.003 & 1.993 & 6.010 & 4,351 & 2,859 \\
\hline & Status quo & 8.645 & 2.047 & 6.597 & 4,552 & 2,950 \\
\hline \multirow[t]{3}{*}{ After 30 years } & Novel TB vaccine at birth with Booster & 10.869 & 2.549 & 8.320 & 5,062 & 3,711 \\
\hline & Novel TB vaccine at birth & 11.294 & 2.377 & 8.917 & 5,261 & 3,836 \\
\hline & Status quo & 12.067 & 2.431 & 9.636 & 5,460 & 3,927 \\
\hline
\end{tabular}




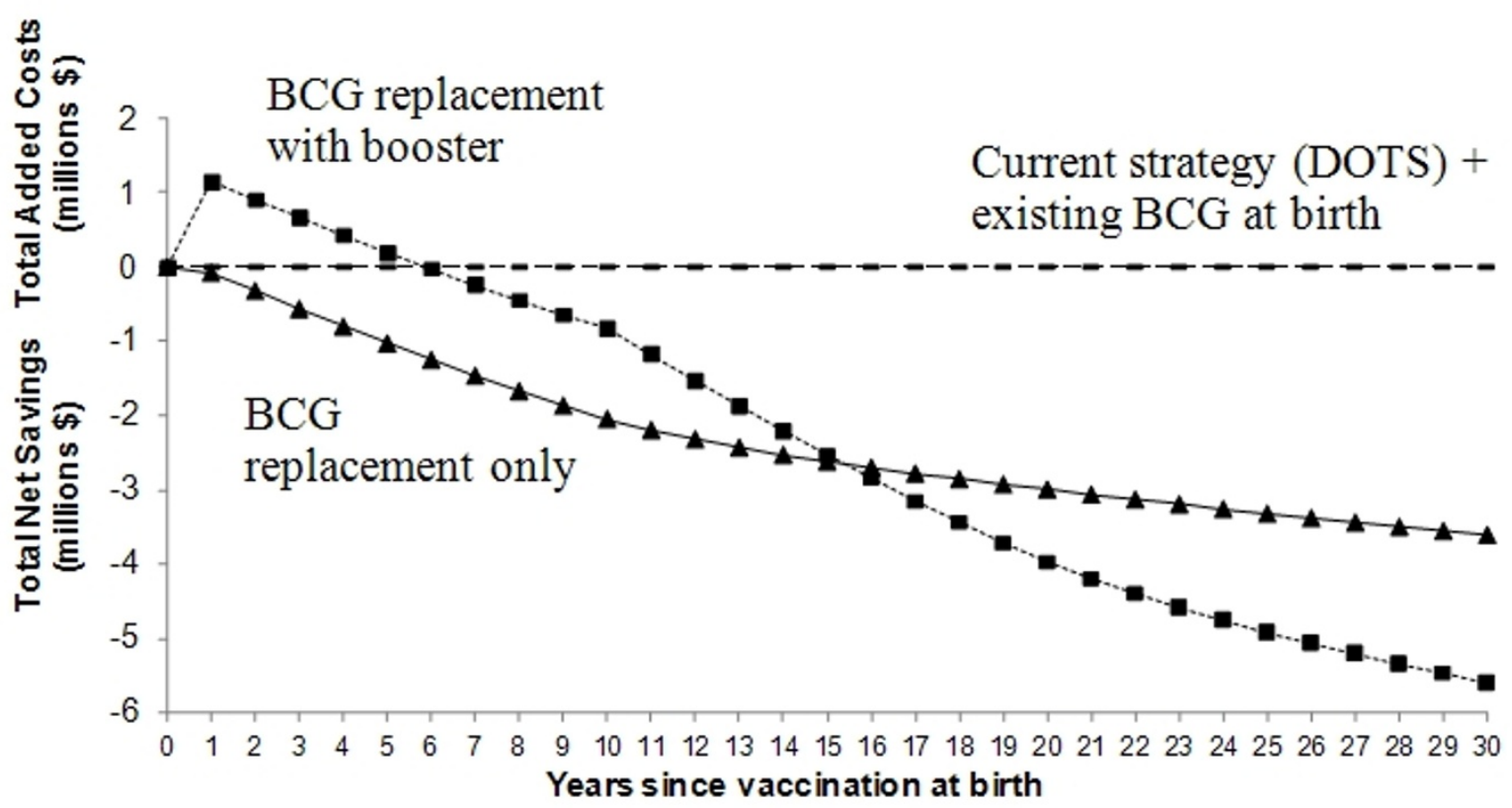

Figure $\mathbf{2}$ Net savings or added cost of vaccine strategies over 30 years relative to status quo.

A previous analysis examined the public health impact of new tuberculosis vaccines and predicted that a preexposure vaccine, targeting the acquisition of infection or primary progression would be effective at preventing a substantial proportion of active TB cases. Although such a vaccine would not benefit persons who have already become infected with Mycobacterium tuberculosis, it would nonetheless provide important public health gains with respect to tuberculosis-related morbidity and mortality. The authors predicted that a pre-exposure vaccine that acts solely by reducing later reactivation of latent infection would not have the same impact, even if the vaccine were highly efficacious [36]. Our findings are similar and concordant with another recent analysis that used different modeling methods [37]. Over the long term, any vaccine that reduces late reactivation will decrease the annual risk of $\mathrm{TB}$ infection and therefore decrease disease incidence. However, the low annual risk of re-activation in HIV-negative persons, combined with finite vaccine duration of action make such a vaccine less cost-effective in the short or medium term.

The cost-effectiveness of a vaccine targeting late reactivation will be enhanced if it provides longer lasting immunity, and potentially if it is administered only after the acquisition of latent infection. One report estimated that a pre-exposure vaccine with efficacy of 50\% - 90\%, with a single mechanism of action, may only be capable of reducing TB morbidity by one third over the long term [36]. However, a more recent analysis concluded that a neonatal vaccine could reduce TB incidence by $39-55 \%$ in the long term, while a mass pre-exposure vaccine campaign could reduce incidence by $67 \%$, in the absence of HIV infection [38]. The same analysis suggested that the combination of pre- and post- exposure vaccines could reduce TB incidence by $79 \%$ in Southeast Asia by 2050, in the absence of HIV infection. Hence, a TB control strategy that combines the DOTS program with vaccines targeting both early infection/progression and late reactivation may ultimately be considered.

The duration of vaccine-induced immunity remains unclear for the current BCG vaccine $[6,39,40]$, so no concrete estimates exist for novel BCG replacement vaccines. For a vaccine with waning efficacy, a prime-boost strategy would be more cost-effective in the long term (Figure 2); however, the time lag to net savings may present a barrier to investment by both the public and private sectors.

A limitation of our analysis was the prorated attribution of the initial vaccine development, research, and production costs to Zambia, in proportion to its current share of global BCG vaccination coverage $(0.398 \%)$. At this point in vaccine development there remains great uncertainty about the ultimate cost of research, pre-clinical and clinical trials, and vaccine rollout. It is quite conceivable that these costs will exceed the estimates used in our primary analysis. However, sensitivity analyses suggested cost savings for the neonatal replacement vaccine, even if the initial investment and vaccine 
Table 6 Sensitivity analysis of vaccine strategies for tuberculosis control in Zambia, for the total cohort of 468,073 newborns

\begin{tabular}{|c|c|c|c|c|}
\hline \multirow[t]{2}{*}{ Parameter Varied } & $\begin{array}{l}\text { No. of TB cases } \\
\text { prevented* }\end{array}$ & $\begin{array}{l}\text { Change in Direct } \\
\text { Costst } \$ \text { million }\end{array}$ & $\begin{array}{l}\text { Change in Indirect } \\
\text { Costst } \$ \text { million }\end{array}$ & $\begin{array}{l}\text { Change in Total } \\
\text { Costst } \$ \text { million }\end{array}$ \\
\hline & \multicolumn{4}{|c|}{ All values are relative to the status quo strategy over 30 years } \\
\hline \multicolumn{5}{|l|}{ Novel TB Vaccine at Birth } \\
\hline Base case (no change in parameters) & 932 & $(\$ 0.25)$ & $(\$ 3.37)$ & $(\$ 3.62)$ \\
\hline Initial investment doubled & 932 & $\$ 0.31$ & $(\$ 3.37)$ & $(\$ 3.06)$ \\
\hline Initial investment quadrupled & 932 & $\$ 1.44$ & $(\$ 3.37)$ & $(\$ 1.93)$ \\
\hline Vaccine unit costs doubled & 932 & $\$ 0.24$ & $(\$ 3.37)$ & $(\$ 3.13)$ \\
\hline Vaccine unit costs quadrupled & 932 & $\$ 1.20$ & $(\$ 3.37)$ & $(\$ 2.17)$ \\
\hline Initial investment \& vaccine unit costs doubled & 932 & $\$ 0.79$ & $(\$ 3.37)$ & $(\$ 2.58)$ \\
\hline Initial investment \& vaccine unit costs quadrupled & 932 & $\$ 2.89$ & $(\$ 3.37)$ & $(\$ 0.48)$ \\
\hline Vaccine duration of action halved (5 yrs) & (98) & $\$ 0.22$ & $\$ 0.33$ & $\$ 0.55$ \\
\hline $\begin{array}{l}\text { Initial investment \& vaccine unit costs doubled \& } \\
\text { vaccine duration of action halved }\end{array}$ & (98) & $\$ 1.26$ & $\$ 0.33$ & $\$ 1.59$ \\
\hline HIV prevalence increased by $50 \%$ & 1,020 & $(\$ 0.28)$ & $(\$ 3.57)$ & $(\$ 3.85)$ \\
\hline HIV prevalence decreased by $50 \%$ & 833 & $(\$ 0.23)$ & $(\$ 3.16)$ & $(\$ 3.39)$ \\
\hline Annual risk of TB infection increased by $50 \%$ & 1,297 & $(\$ 0.41)$ & $(\$ 4.67)$ & $(\$ 5.08)$ \\
\hline Annual risk of TB infection decreased by $50 \%$ & 501 & $(\$ 0.06)$ & $(\$ 1.83)$ & $(\$ 1.89)$ \\
\hline Discount rate $2 \%$ annually & 936 & $(\$ 0.26)$ & $(\$ 3.79)$ & $(\$ 4.05)$ \\
\hline Discount rate $6 \%$ annually & 899 & $(\$ 0.23)$ & $(\$ 2.46)$ & $(\$ 2.69)$ \\
\hline \multicolumn{5}{|l|}{ Novel TB Vaccine at Birth with Booster } \\
\hline Base case (no change in parameters) & 1,863 & $\$ 0.55$ & $(\$ 6.16)$ & $(\$ 5.61)$ \\
\hline Initial investment doubled & 1,863 & $\$ 1.33$ & $(\$ 6.16)$ & $(\$ 4.83)$ \\
\hline Initial investment quadrupled & 1,863 & $\$ 2.87$ & $(\$ 6.16)$ & $(\$ 3.29)$ \\
\hline Vaccine unit costs doubled & 1,863 & $\$ 2.05$ & $(\$ 6.16)$ & $(\$ 4.11)$ \\
\hline Vaccine unit costs quadrupled & 1,863 & $\$ 5.05$ & $(\$ 6.16)$ & $(\$ 1.11)$ \\
\hline Initial investment \& vaccine unit costs doubled & 1863 & $\$ 2.82$ & $(\$ 6.16)$ & $(\$ 3.34)$ \\
\hline Initial investment \& vaccine unit costs quadrupled & 1,863 & $\$ 7.36$ & $(\$ 6.16)$ & $\$ 1.20$ \\
\hline Vaccine duration of action halved (5 yrs) & 904 & $\$ 0.98$ & $(\$ 3.18)$ & $(\$ 2.20)$ \\
\hline $\begin{array}{l}\text { Initial investment \& vaccine unit costs doubled \& } \\
\text { vaccine duration of action halved }\end{array}$ & 904 & $\$ 3.25$ & $(\$ 3.18)$ & $\$ 0.07$ \\
\hline HIV prevalence increased by $50 \%$ & 1,994 & $\$ 0.53$ & $(\$ 6.48)$ & $(\$ 5.95)$ \\
\hline HIV prevalence decreased by $50 \%$ & 1,718 & $\$ 0.58$ & $(\$ 5.81)$ & $(\$ 5.23)$ \\
\hline Annual risk of TB infection increased by $50 \%$ & 2,294 & $\$ 0.37$ & $(\$ 7.64)$ & $(\$ 7.27)$ \\
\hline Annual risk of TB infection decreased by $50 \%$ & 1,151 & $\$ 0.87$ & $(\$ 3.78)$ & $(\$ 2.91)$ \\
\hline Discount rate $2 \%$ annually & 1,985 & $\$ 0.59$ & $(\$ 7.15)$ & $(\$ 6.56)$ \\
\hline Discount rate $6 \%$ annually & 1,568 & $\$ 0.45$ & $(\$ 4.09)$ & $(\$ 3.64)$ \\
\hline
\end{tabular}

*For TB cases prevented, values in parentheses indicate a net increase in TB cases.

†For costs: values in parentheses indicate net savings, values without parentheses indicate net cost increases.

unit costs were both quadrupled. Our prorating of development costs to a single cohort of newborns is also conservative, as it tends to underestimate the cost-effectiveness of TB vaccines over time.

In fact, high-incidence low- and middle- income countries which will use novel TB vaccines may bear little of their initial development costs. The funds may be provided primarily by governments of high-income countries, non-governmental organizations and research grants. This means that from the perspective of highincidence countries and their populations, novel tuberculosis vaccines will be even more cost-effective. On the other hand, from the broader global TB control perspective, which includes costs to funders, these costs are relevant to the present analysis.

We did not model potential adverse events related to the administration of tuberculosis vaccines in neonates. An open-label, phase I trial of a novel vaccine candidate has demonstrated safety and high immunogenicity in individuals with latent tuberculosis infection [41]. The frequency of disseminated BCG has been reported to be less than five per million, and is mainly associated with congenital immunocompromised states [42]. A recent revision to the $\mathrm{WHO}$ guidelines on $\mathrm{BCG}$ vaccination 


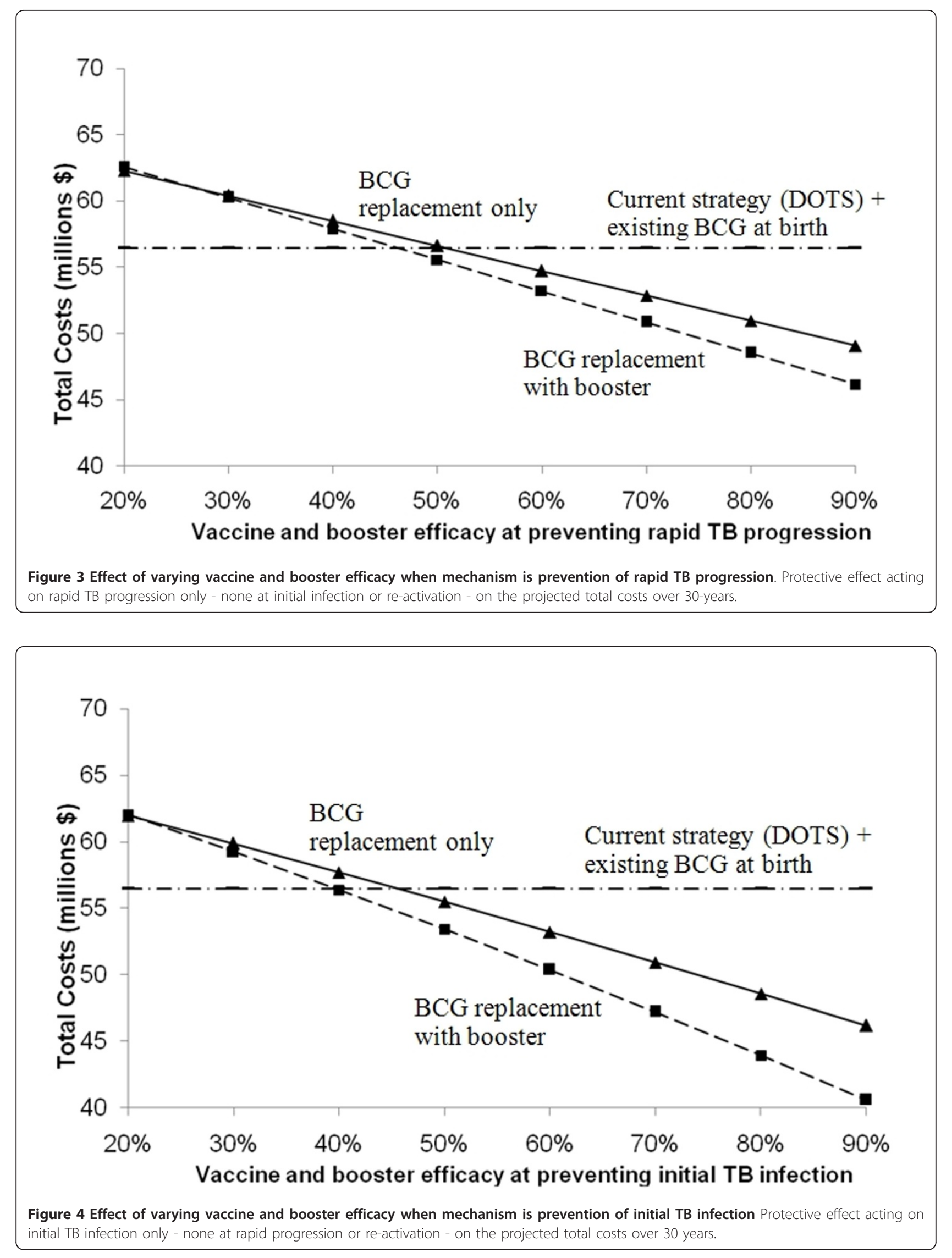




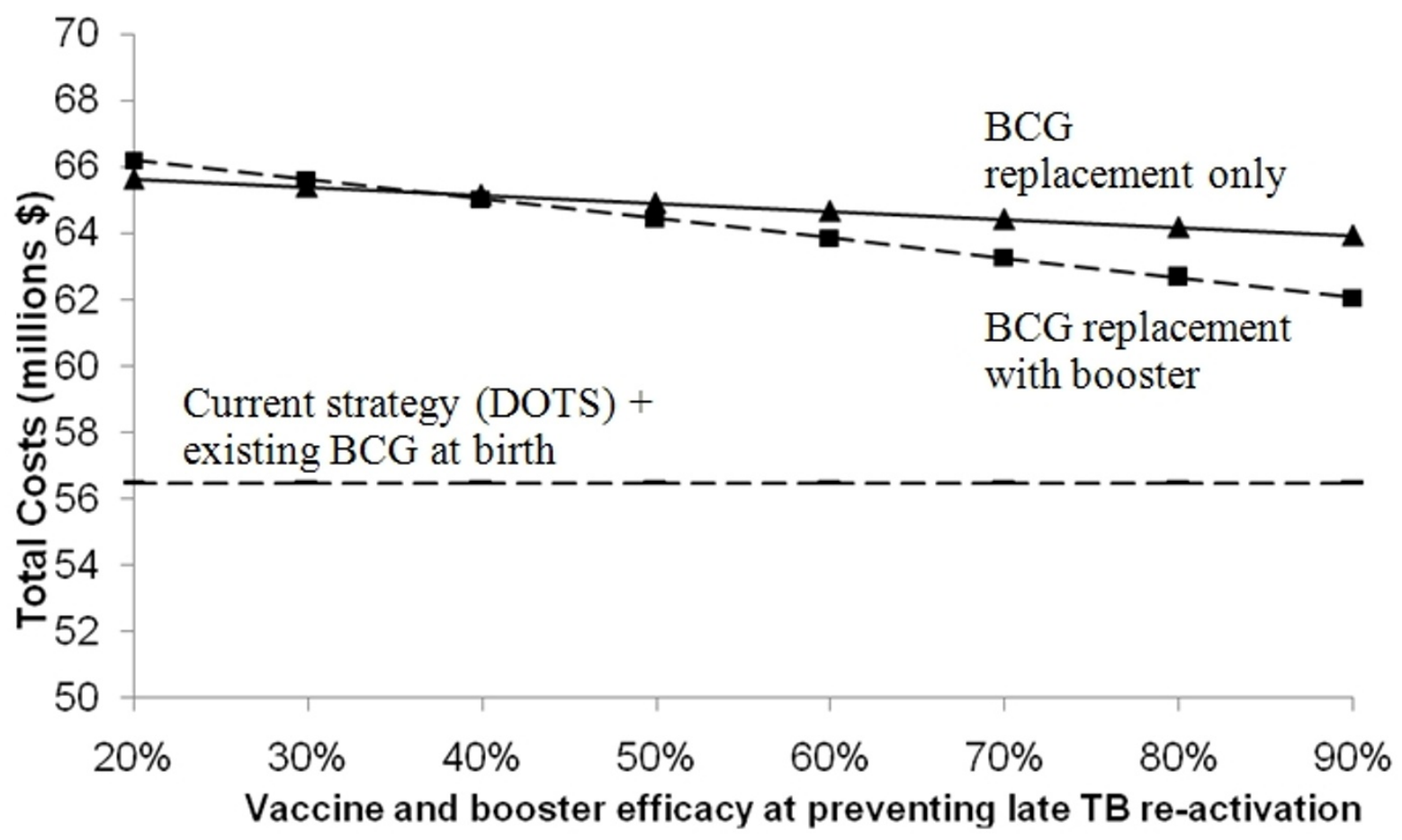

Figure 5 Effect of varying vaccine and booster efficacy when mechanism is prevention of late TB re-activation. Protective effect acting on late TB re-activation only - none at initial infection or rapid progression - on the projected total costs over 30 years.

recommends the immunization of asymptomatic infants whose HIV status is unknown, but advises against immunization of 1) infants whose HIV status is unknown, but display signs or symptoms suggestive of HIV infection; and 2) HIV positive infants, regardless of signs or symptoms [43]. A previous study showed that the risk of disseminated BCG disease is increased several hundredfold in HIV-infected infants compared to the documented risk in HIV-uninfected infants [44]. Unfortunately, due to the transplacental passage of maternal HIV antibodies, accurate diagnosis in the neonatal period requires the demonstration of HIV DNA, or HIV RNA and p24 antigen. Furthermore, signs of HIV infection are uncommon prior to BCG vaccine administration in the first weeks of life. For these reasons, the current program for BCG vaccination may have reduced efficacy in a particularly high-risk group, and increased morbidity, mortality, and added costs may result from BCG-related adverse events in countries with high HIV prevalence such as Zambia. Conversely, safety in HIVinfected neonates is considered a prerequisite for any future neonatal TB vaccine.

Other potential limitations of the analysis included our assumptions of stability in population size and age distribution, and HIV parameters. Herd immunity was not modeled [45], but a reduction in the annual risk of TB infection resulting from any vaccine which prevents contagious pulmonary $\mathrm{TB}$ would further reduce $\mathrm{TB}$ morbidity and mortality. Similarly, we did not model transmission, since the primary analysis considered vaccine protection among children, in whom TB is rarely contagious. Again, this makes our model conservative in that it tends to underestimate potential vaccine benefits.

A challenge to TB vaccine development is the lack of proven immunological correlates of vaccine-induced immunity, although early animal studies suggest improved protection against a pulmonary TB challenge for several prime-boost approaches [46-48]. We did not model the effects of $M$. tuberculosis strain diversity. A recent analysis suggests the efficacy of novel vaccines may differ against different strains of the bacteria [49], however, the precise impact on efficacy remains uncertain given our incomplete knowledge regarding how distinct strains interact and the strain specificity of current vaccine candidates.

Our findings remained consistent across different scenarios for HIV seroprevalence. Greater savings and reduction in TB-related morbidity and mortality would be achieved if HIV seroprevalence was higher, owing to the more frequent development of active TB following 
infection. An increase in the proportion of TB which is multi-drug resistant would yield greater cost savings for vaccination, because of increased treatment and patient/ family costs for MDR-TB. We computed the annual risk of TB infection from the incidence of smear-positive cases using the Styblo formula, which has been criticized [50]. Furthermore, a recent study has shown that in the presence of a strong control program, the TB incidence is not necessarily reflective of the true annual risk of TB infection in a country with high HIV seroprevalence [51]. However, we substantially varied the assumed annual risk of TB infection, and demonstrated that both primary vaccination strategies considered would still result in cost savings. Any inaccuracy in estimating the annual risk of TB infection would apply equally to all strategies, and would not tend to favor one particular strategy over the others.

Health care system costs were approximated by previously published data in Haiti, where GNI per capita is similar to Zambia. Social, political, and economic differences between the two countries may affect the validity of these estimates. However, indirect costs, which were obtained from Zambia itself, accounted for the bulk of total societal costs, strengthening our cost estimates. As a case study, our results may not be directly applicable to other sub-Saharan African countries given variability in epidemiology and economics, but the flexibility of the decision analysis model suggests the potential for a similar approach.

Several strengths of the analysis deserve comment. We considered the effect of HIV infection on TB pathogenesis, and accounted for survival with asymptomatic HIV and clinical AIDS, since HIV prevalence is high in Zambia and other sub-Saharan African countries [10]. Published values were used for epidemiologic data, TB pathogenesis, HIV pathogenesis, and treatment outcomes whenever available, thereby reducing uncertainty. We evaluated costs from a societal perspective, and considered both direct and indirect costs from the standpoint of a low-income country with high TB incidence. Notably, indirect costs borne by patients and families constituted a substantial proportion of the total. The decision analysis model allowed us to manipulate key variables and test our underlying assumptions. Sensitivity analyses confirmed the robustness of the main findings. In particular, with an assumed efficacy of $60 \%$, a novel vaccine that prevents rapid progression to active TB would still provide cost savings, as well as prevent TB cases and TB-related deaths. This strengthens the economic argument in favour of developing and implementing new vaccines. We recognize that the $70 \%$ efficacy estimate used for our primary analysis is speculative, as useful evidence must await the outcome of one or more large-scale clinical trials, still years away.
Novel TB vaccine development and deployment faces a number of obstacles. The lack of validated biomarkers for candidate vaccine selection, scarcity of suitable field sites, exclusion of at-risk populations from trials, regulatory issues, and complex ethical concerns at each stage of human testing are among the challenges [52-54]. The continued expansion of the TB vaccine pipeline, however, remains reassuring. Recent years have renewed interest in TB vaccine development. By the end of 2009, at least nine novel TB vaccines were undergoing evaluation in humans, with at least two recombinant protein vaccines reaching phase II trials $[54,55]$.

\section{Conclusions}

This analysis suggests that a prime-boost strategy using a tuberculosis vaccine with moderate efficacy $(>60 \%)$ which prevents initial infection or rapid primary progression to disease, will be the most cost-effective vaccine intervention over the short to medium term, in high-burden countries. We conclude that investment in an improved $\mathrm{TB}$ vaccine may result in considerable cost savings, as well as a reduction in TB morbidity and TB-related mortality, when it enhances existing control strategies.

\section{Acknowledgements}

The authors gratefully acknowledge the assistance of Ms. Esther TomKee with manuscript preparation.

Dr. Tseng was supported by a summer studentship award from the McGill University Faculty of Medicine. Ms. Oxlade was supported by a doctoral research award from the Canadian Institutes of Health Research. Dr. Menzies was supported by a Chercheur National career award, and Dr. Schwartzman by a Chercheur Boursier-Clinicien career award, both from the Fonds de la Recherche en Santé du Québec. These funding bodies had no role in the design or conduct of the study, or in the preparation and submission of this manuscript.

\section{Author details}

${ }^{1}$ Respiratory Epidemiology and Clinical Research Unit, Montreal Chest Institute, Montreal, Canada. ${ }^{2}$ Faculty of Medicine, McGill University, Montreal, QC, Canada. ${ }^{3}$ Department of Epidemiology, Biostatistics, and Occupational Health, McGill University, Montreal, QC, Canada. ${ }^{4}$ Respiratory Division, McGill University, Montreal, QC, Canada. ${ }^{5}$ Internal Medicine Residency Training Program, Faculty of Medicine, University of Toronto, Toronto, ON, Canada.

\section{Authors' contributions}

C-LT aided in design of the study, acquired study data, conducted the primary analyses, and wrote the first draft of the manuscript. $\mathrm{OO}$ aided in design of the study and acquisition of data, aided the analyses, and provided critical revisions to the manuscript. DM aided in design of the study and in acquisition and analysis of data, and provided critical revisions to the manuscript. AA aided in study design, acquisition and analysis of data, and provided critical revisions to the manuscript. KS supervised study design, data acquisition and analysis, and helped draft and critically revise the manuscript. All authors have read and approved the final manuscript.

\section{Competing interests}

The authors declare that they have no competing interests.

Received: 27 August 2010 Accepted: 26 January 2011 Published: 26 January 2011 


\section{References}

1. Global tuberculosis control: epidemiology, strategy, financing. $\mathrm{WHO}$ report 2009 Geneva: WHO Press; 2009.

2. Meulemans H, Mortelmans D, Liefooghe R, Mertens P, Zaidi SA, Solangi MF, De Muynck A: The limits to patient compliance with directly observed therapy for tuberculosis: a socio-medical study in Pakistan. Int J Health Plann Manage 2002, 17:249-267.

3. Elzinga G, Raviglione MC, Maher D: Scale up: meeting targets in global tuberculosis control. Lancet 2004, 363:814-819.

4. Bonnet $M$, Sizaire $V$, Kebede $Y$, Janin A, Doshetov D, Mirzoian B, Arzumanian A, Muminov T, lona E, Rigouts L, Rüsch-Gerdes S, Varaine F: Does one size fit all? Drug resistance and standard treatments: results of six tuberculosis programmes in former Soviet countries. Int J Tuberc Lung Dis 2005, 9:1147-1154.

5. Global Plan to Stop TB 2006-2015. Stop TB Partnership and World Health Organization. Geneva, World Health Organization; 2006, (WHO/HTM/STB/ 2006.35).

6. Colditz GA, Berkey CS, Mosteller F, Brewer TF, Wilson ME, Burdick E, Fineberg HV: The efficacy of bacillus Calmette-Guérin vaccination of newborns and infants in the prevention of tuberculosis: meta-analysis of the published literature. Pediatrics 1995, 96:29-35.

7. Rodrigues LC, Diwan VK, Wheeler JG: Protective effect of BCG against tuberculous meningitis and military tuberculosis: a meta-analysis. Int $J$ Epidemiol 1993, 22:1154-1158.

8. Skeiky YA, Sadoff JC: Advances in tuberculosis vaccine strategies. Nat Rev Microbiol 2006, 4:469-476.

9. Menzies D: A survey of vaccine technology. Presentation at 36th Union World Conference on lung health, Paris, France 2005.

10. UNAIDS. 2006 Report on the global AIDS epidemic [http://www.unaids.org/ en/KnowledgeCentre/HIVData/GlobalReport/2006/default.asp].

11. Weinstein MC, Siegel JE, Gold MR, Kamlet MS, Russell LB: Recommendations of the Panel on cost-effectiveness in health and medicine. JAMA 1996, 276:1253-1258.

12. Brewer TF: Preventing tuberculosis with bacillus Calmette-Guérin vaccine: a meta-analysis of the literature. Clin Infect Dis 2000, 31(Suppl 3):64-67.

13. Colditz GA, Brewer TF, Berkey CS, Wilson ME, Burdick E, Fineberg HV, Mosteller F: Efficacy of BCG vaccine in the prevention of tuberculosis. Meta-analysis of the published literature. JAMA 1994, 271:698-702.

14. Schwartzman K, Oxlade O, Barr RG, Grimard F, Acosta I, Baez J, Ferreira E, Melgen RE, Morose W, Salgado AC, Jacquet V, Maloney S, Laserson K, Mendez AP, Menzies D: Domestic returns from investment in the control of tuberculosis in other countries. N Engl J Med 2005, 353:1008-1020.

15. Jacquet V, Morose W, Schwartzman K, Oxlade O, Barr G, Grimard F, Menzies D: Impact of DOTS expansion on tuberculosis related outcomes and costs in Haiti. BMC Public Health 2006, 6:209.

16. Styblo K: The relationship between the risk of tuberculosis infection and the risk of developing infectious tuberculosis. Bull Int Union Tuberc 1985, 60:117-119.

17. Sutherland I: The evolution of clinical tuberculosis in adolescents. Tuberc $1966,47: 308$.

18. Nolan CM, Elarth AM: Tuberculosis in a cohort of Southeast Asian refugees. A five-year surveillance study. Am Rev Respir Dis 1988, 137:805-809

19. Comstock GW, Edwards LB, Livesay VT: Tuberculosis morbidity in the U.S. Navy: its distribution and decline. Am Rev Respir Dis 1974, 110:572-580.

20. Burgess AL, Fitzgerald DW, Severe P, Joseph P, Noel E, Rastogi N, Johnson WD Jr, Pape JW: Integration of tuberculosis screening at an HIV voluntary counselling and testing centre in Haiti. AIDS 2001, 15:1875-79.

21. Dasgupta K, Schwartzman K, Marchand R, Tannenbaum TN, Brassard P, Menzies D: Comparison of cost effectiveness of tuberculosis screening of close contacts and foreign-born populations. Am J Respir Crit Care Med 2000, 162:2079-2086.

22. Morgan D, Mahe C, Mayanja B, Okongo JM, Lubega R, Whitworth JA: HIV-1 infection in rural Africa: is there a difference in median time to AIDS and survival compared with that in industrialized countries? AIDS 2002, 16:597-603.

23. Wood R, Maartens G, Lombard CJ: Risk factors for developing tuberculosis in HIV-1-infected adults from communities with low or very high incidence of tuberculosis. J Acquir Immune Defic Syndr 2000, 23:75-80.

24. Murray J, Sonnenberg P, Shearer SC, Godgrey-Faussett P: Human immunodeficiency virus and outcome of treatment for new and recurrent pulmonary tuberculosis in African patients. Am J Respir Crit Care Med 1999, 159:733-740.

25. Edlin BR, Tokars Jl, Grieco MH, Crawford JT, Williams J, Sordillo EM, Ong KR, Kilburn JO, Dooley SW, Castro KG, Jarvis WR, Holmberg SD: An outbreak of multi-drug resistant tuberculosis among hospitalized patients with the acquired immunodeficiency syndrome. New Engl J Med 1992, 326:1514-1521.

26. Malkin JE, Prazuck T, Simonnet F, Yameogo M, Rochereau A, Ayerour J, Masson D, Lafaix C: Tuberculosis and human immunodeficiency virus infection in West Burkina Faso: clinical presentation and clinical evolution. Int J Tuberc Lung Dis 1997, 1:68-74.

27. Aspler A, Menzies D, Oxlade O, Banda J, Mwenge L, Godfrey-Faussett P, Ayles $\mathrm{H}$ : Cost of tuberculosis diagnosis and treatment from the patient perspective in Lusaka, Zambia. Int J Tuberc Lung Dis 2008, 12:928-935.

28. Sherman LF, Fujiwara PI, Cook SV, Bazerman LB, Frieden TR: Patient and health care system delays in the diagnosis and treatment of tuberculosis. Int J Tuberc Lung Dis 1999, 3:1088-1095.

29. Yamasaki-Nakagawa M, Ozasa K, Yamada N, Osuga K, Shimouchi A, Ishikawa N, Bam DS, Mori T: Gender difference in delays to diagnosis and health care seeking behaviour in a rural area of Nepal. Int J Tuberc Lung Dis 2001, 5:24-31.

30. Wandwalo ER, Morkve O: Delay in tuberculosis case-finding and treatment in Mwanza, Tanzania. Int J Tuberc Lung Dis 2000, 4:133-138.

31. Vaca J, Peralta H, Gresely L, Cordova R, Kuffo D, Romero E, Tannenbaum TN, Houston S, Graham B, Hernandez L, Menzies D: DOTS implementation in a middle-income country: development and evaluation of a novel approach. Int J Tuberc Lung Dis 2005, 9:521-527.

32. U.S. Department of Labor Statistics. Consumer price index 2007 [http:// www.stats.bls.gov]

33. Stop TB Partnership Global Drug Facility: Stop TB Partnership. First-Line tuberculosis drugs \& formulations currently supplied/to be supplied by the global TB drug facility, Geneva 2007 [http://www.stoptb.org/gdf/].

34. World Health Organization. Vaccine Preventable Diseases Monitoring System 2007 [http://www.who.int/vaccines/globalsummary/immunization/ countryprofileselect.cfm].

35. Baumann S, Nasser Eddine A, Kaufmann SH: Progress in tuberculosis vaccine development. Curr Opin Immunol 2006, 18:438-448, Epub 2006 Jun 13.

36. Ziv E, Daley CL, Blower S: Potential public health impact of new tuberculosis vaccines. Emerg Infect Dis 2004, 10:1529-1535.

37. Bhunu CP, Garira W, Mukandavire Z, Magombedze G: Modelling the effects of pre-exposure and post-exposure vaccines in tuberculosis control. Journal of Theoretical Biology 2008, 254:633-649.

38. Abu-Raddad LJ, Sabatelli L, Achterberg JT, Sugimoto JD, Longini IM Jr Dye C, Halloran ME: Epidemiological benefits of more-effective tuberculosis vaccines, drugs, and diagnostics. Proc Natl Acad Sci USA 2009, 106:13980-13985, Epub 2009 Aug 3.

39. Aronson NE, Santosham M, Comstock GW, Howard RS, Moulton LH, Rhoades ER, Harrison LH: Long-term efficacy of BCG vaccine in American Indians and Alaska Natives: A 60-year follow-up study. JAMA 2004, 291:2086-2091.

40. Fine PE: Variation in protection by BCG: implications of and for heterologous immunity. Lancet 1995, 346:1339-1345.

41. Sander CR, Pathan AA, Beveridge NE, Poulton I, Minassian A, Alder N, Hill AV, McShane H: Safety and immunogenicity of a new tuberculosis vaccine, MVA85A, in Mycobacterium tuberculosis-infected individuals. Am J Respir Crit Care Med 2009, 179:724-733.

42. Casanova $J$, Jouanguy $E$, Lamhamedi S, Blanche S, Fischer A: Immunological conditions of children with BCG disseminated infection. Lancet 1995, 346:581.

43. WHO: Revised BCG vaccination guidelines for infants at risk for HIV infection. Weekly Epidemiological Record 2007, 82:193-196.

44. Hesseling AC, Marais BJ, Gie RP, Schaaf HS, Fine PE, Godfrey-Faussett P, Beyers N: The risk of disseminated Bacille Calmette-Guerin (BCG) disease in HIV-infected children. Vaccine 2007, 25:14-18, Epub 2006 Aug 1.

45. Brisson M, Edmunds WJ: Economic evaluation of vaccination programs: The impact of herd-immunity. Med Decis Making 2003, 23:76-82.

46. Brooks JV, Frank AA, Keen MA, Bellisle JT, Orme IM: Boosting vaccine for tuberculosis. Infect Immun 2001, 69:2714-2717.

47. Goonetilleke NP, McShane H, Hannan CM, Anderson RJ, Brookes RH, Hill AV: Enhanced immunogenicity and protective efficacy against 
Mycobacterium tuberculosis of bacille Calmette-Guérin vaccine using mucosal administration and boosting with a recombinant modified vaccinia virus Ankara. J Immunol 2003, 171:1602-1609.

48. Wang J, Thorson L, Stokes RW, Santosuosso M, Huygen K, Zganiacz A, Hitt $M$, Xing Z: Single mucosal, but not parenteral, immunization with recombinant adenoviral-based vaccine provides potent protection from pulmonary tuberculosis. J Immunol 2004, 173:6357-6365.

49. Cohen T, Colijn C, Murray M: Modeling the effects of strain diversity and mechanisms of strain competition on the potential performance of new tuberculosis vaccines. PNAS 2008, 105:16302-16307.

50. van Leth F, van der Werf MJ, Borgdorff MW: Prevalence of tuberculous infection and incidence of tuberculosis: a re-assessment of the Styblo rule. Bull World Health Organ 2008, 86:20-26.

51. Egwaga SM, Cobelens FG, Muwinge $H$, Verhage C, Kalisvaart $N$, Borgdorff MW: The impact of the HIV epidemic on tuberculosis transmission in Tanzania. AIDS 2006, 20:915-921.

52. Fletcher HA, Hawkridge T, McShane H: A new vaccine for Tuberculosis: The challenges of development and deployment. J Bioeth Ing 2009, 6:219-228.

53. Wallis RS, Wang C, Doherty TM, Onyebujoh P, Vahedi M, Laang $H$, Olesen $O$ Parida S, Zumla A: Biomarkers for tuberculosis disease activity, cure, and relapse. Lancet Infect Dis 2009, 9:162-72.

54. Aagaard C, Dietrich J, Doherty M, Andersen P: TB vaccines: current status and future perspectives Immunol Cell Biol. 2009, 87:279-286, Epub 2009 Apr 7.

55. Working Group on new TB Vaccines: Stop TB Partnership. TB Vaccine Pipeline 2009 [http://www.stoptb.org/wg/new_vaccines/assets/documents/ TB\%20Vaccine\%20Pipeline\%2009\%20final.pdf].

56. United Nations Populations Division. World population prospects: the 2006 revision [http://esa.un.org/unpp/].

57. CIA - The World Factbook. The World Factbook. Zambia 2007 [https:// www.cia.gov/library/publications/the-world-factbook/geos/za.html].

58. The World Bank Group. Zambia Data Profile 2007 [http://web.worldbank. org/WBSITE/EXTERNAL/COUNTRIES/AFRICAEXT/ZAMBIAEXTN/0, menuPK:375673 pagePK:141159 piPK:141110 theSitePK:375589,00.html]

59. World Health Organization. Life tables for WHO member states 2007 [http://www.who.int/whosis/database/life_tables/life_tables.cfm].

60. Anti-tuberculosis drug resistance in the world. WHO report 2004, Geneva 2004.

61. Zignol M, Hosseini MS, Wright A, Weezenbeek CL, Nunn P, Watt CJ, Williams BG, Dye C: Global incidence of multidrug-resistant tuberculosis. Infect Dis 2006, 194:479-485.

62. Deschamps MM, Fitzgerald DW, Pape JW, Johnson WD Jr: HIV infection in Haiti: natural history and disease progression. AIDS 2000, 14:2515-2521.

63. Grzybowski S, Barnett GD, Styblo K: Contacts of cases of active pulmonary tuberculosis. Bull Int Union Tuberc 1975, 50:90-106.

64. Menzies D: Issues in the management of contacts of patients with active pulmonary tuberculosis. Can J Public Health 1997, 88:197-201.

65. Stead WW: Management of health care workers after inadvertent exposure to tuberculosis: a guide for the use of preventive therapy. Ann Intern Med 1995, 122:906-12.

66. Whalen CC, Johnson JL, Okwera A, Hom DL, Huebner R, Mugyenyi P, Mugerwa RD, Ellner JJ: A trial of three regimens to prevent tuberculosis in Ugandan adults infected with the human immunodeficiency virus. Uganda-Case Western Reserve University Research Collaboration. Engl J Med 1997, 337:801-808.

67. Guelar A, Gatell JM, Verdejo J, Podzamczer D, Lozano L, Aznar E, Miro JM, Mallolas J, Zamora L, Gonzalez J, Sorano E: A prospective study of the risk of tuberculosis among HIV-infected patients. AIDS 1993, 7:1345-1349.

68. Beck-Sagué C, Dooley SW, Hutton MD, Otten J, Breeden A, Crawford JT, Pitchenik AE, Woodley C, Cauthen G, Jarvis WR: Hospital outbreak of multidrug-resistant Mycobacterium tuberculosis infections. Factors in transmission to staff and HIV-infected patients. JAMA 1992, 268:1280-1286

69. Fischl MA, Uttamchandani RB, Daikos GL, Poblete RB, Moreno JN, Reyes RR, Boota AM, Thompson LM, Cleary TJ, Lai S: An outbreak of tuberculosis caused by multiple-drug-resistant tubercle bacilli among patients with HIV infection. Ann Intern Med 1992, 117:177-183.

70. Small PM, Shafer RW, Hopewell PC, Singh SP, Murphy MJ, Desmond E, Sierra MF, Schoolnik GK: Exogenous reinfection with multidrug-resistant
Mycobacterium tuberculosis in patients with advanced HIV infection. $N$ Engl J Med 1993, 328:1137-1144

71. Daley CL, Small PM, Schecter GF, Schoolnik GK, McAdam RA, Jacobs WR Jr Hopewell PC: An outbreak of tuberculosis with accelerated progression among persons infected with the human immunodeficiency virus: An analysis using restriction-fragment-length polymorphisms. N Engl J Med 1992, 326:231-235.

72. Grzybowski S, Enarson DA: The fate of cases of pulmonary tuberculosis under various treatment programmes. Bull Int Union Tuberc 1978, 53:70-74.

73. Horwitz O: Public health aspects of relapsing tuberculosis. Am Rev Respir Dis 1969, 99:183-193.

74. Reider HL: Epidemiologic basis of tuberculosis control. Paris, France, International Union Against Tuberculosis and Lung Disease; First 1999 $1-162$.

75. Cohn DL, Catlin BJ, Peterson KL, Judson FN, Sbarbaro JA: A 62-dose, 6month therapy for pulmonary and extrapulmonary tuberculosis. A twice-weekly, directly observed, and cost-effective regimen. Ann Intern Med 1990, 112:407-415.

76. East African Tuberculosis Investigation Centre, British Medical Research Council Tuberculosis and Chest Diseases Unit: Results at 5 years of a controlled comparison of a 6-month and a standard 18-month regimen of chemotherapy for pulmonary tuberculosis. Am Rev Respir Dis 1977, 116:3-8.

77. Somner AR: Short-course chemotherapy in pulmonary tuberculosis. A controlled trial by the British Thoracic Association (third report). Lancet 1980, 1:1182-1183.

78. Algerian Working Group, British Medical Research Council: Controlled clinical trial comparing a 6-month and a 12-month regimen in the treatment of pulmonary tuberculosis in the Algerian Sahara. Am Rev Respir Dis 1984, 129:921-928.

79. Benator D, Bhattacharya M, Bozeman L, Burman W, Cantazaro A, Chaisson R, Gordin F, Horsburgh CR, Horton J, Khan A, Lahart C, Metchock B, Pachucki C, Stanton L, Vernon A, Villarino ME, Wang YC, Weiner M, Weis S, Tuberculosis Trials Consortium: Rifapentine and isoniazid once a week versus rifampicin and isoniazid twice a week for treatment of drugsusceptible pulmonary tuberculosis in HIV-negative patients: a randomised clinical trial. Lancet 2002, 360:528-534.

80. Chee CBE, Boudville IC, Chan SP, Zee YK, Wang YT: Patient and disease characteristics, and outcome of treatment defaulters from the Singapore TB control unit - a one-year retrospective survey. Int J Tuber Lung Dis 2000, 4:496-503.

81. Parthasarathy $R$, Prabhakar R, Somasundaram PR: A controlled clinical trial of 3- and 5- month regimens in the treatment of sputum-positive pulmonary tuberculosis in South India. Am Rev Respir Dis 1986, 134:27-33.

82. East African Tuberculosis Investigation Centre, British Medical Research Council: Controlled clinical trial of five short-course (4-month) chemotherapy regimens in pulmonary tuberculosis: Second report of the 4th study. Am Rev Respir Dis 1981, 123:165-170.

83. Singapore Tuberculosis Service, British Medical Research Council: Long-term Follow-up of a clinical trial of six-month and four-month regimens of chemotherapy in the treatment of pulmonary tuberculosis. Am Rev Respir Dis 1986, 133:779-83.

84. Espinal MA, Kim SJ, Suarez PG, Kam KM, Khomenko AG, Migliori GB, Baéz J Kochi A, Dye C, Raviglione MC: Standard short-course chemotherapy for drug-resistant tuberculosis: treatment outcomes in 6 countries. JAMA 2000, 283:2537-2545.

85. Nathanson E, Lambregts-van Weezenbeek C, Rich ML, Gupta R, Bayona J, Blöndal K, Caminero JA, Cegielski JP, Danilovits M, Espinal MA, Hollo V, Jaramillo E, Leimane V, Mitnick CD, Mukherjee JS, Nunn P, Pasechnikov A, Tupasi T, Wells C, Raviglione MC: Multidrug-resistant tuberculosis management in resource-limited settings. Emerg Infect Dis 2006, 12:1389-1397.

86. Chaisson RE, Clermont HC, Holt EA, Cantave M, Johnson MP, Atkinson J, Davis H, Boulos R, Quinn TC, Halsey NA: Six-month supervised intermittent tuberculosis therapy in Haitian patients with and without HIV infection. Am J Respir Crit Care Med 1996, 154:1034-1038.

87. Desvarieux M, Hyppolite PR, Johnson WD Jr, Pape JW: A novel approach to directly observed therapy for tuberculosis in an HIV-endemic area. Am J Public Health 2001, 91:138-141. 
88. Johnson JL, Okwera A, Vjecha MJ, Byekwaso F, Nakibali J, Nyole S, Milberg J, Aisu T, Whalen CC, Mugerwa RD, Ellner JJ: Risk factors for relapse in human immunodeficiency virus type 1 infected adults with pulmonary tuberculosis. Int J Tuberc Lung Dis 1997, 1:446-453.

89. Sonnenberg P, Murray J, Glynn JR, Shearer S, Kambashi B, GodfreyFaussett P: HIV-1 and recurrence, relapse, and reinfection of tuberculosis after cure: a cohort study in South African mineworkers. Lancet 2001, 358:1687-1693.

90. Pulido F, Peña JM, Rubio R, Moreno S, González J, Guijarro C, Costa JR, Vázquez JJ: Relapse of tuberculosis after treatment in human immunodeficiency virus-infected patients. Arch Intern Med 1997, 157:227-231

91. Cummings KC, Mohle-Boetani J, Royce SE, Chin DP: Movement of tuberculosis patients and the failure to complete antituberculosis treatment. Am J Respir Crit Care Med 1998, 157:1249-1252.

92. Roos BR, van Cleeff MRA, Githui WA, Kivihya-Ndugga L, Odhiambo JA, Kibuga DK, Klatser PR: Cost-effectiveness of the polymerase chain reaction versus smear examination for the diagnosis of tuberculosis in Kenya: a theoretical model. Int I Tuber Lung Dis 1997, 2:235-241.

93. Trunz BB, Fine P, Dye C: Effect of BCG vaccination on childhood tuberculous meningitis and miliary tuberculosis worldwide: a metaanalysis and assessment of cost-effectiveness. Lancet 2006, 367:1173-1180.

\section{Pre-publication history}

The pre-publication history for this paper can be accessed here: http://www.biomedcentral.com/1471-2458/11/55/prepub

doi:10.1186/1471-2458-11-55

Cite this article as: Tseng et al.: Cost-effectiveness of novel vaccines for tuberculosis control: a decision analysis study. BMC Public Health 2011 11:55.

\section{Submit your next manuscript to BioMed Central and take full advantage of:}

- Convenient online submission

- Thorough peer review

- No space constraints or color figure charges

- Immediate publication on acceptance

- Inclusion in PubMed, CAS, Scopus and Google Scholar

- Research which is freely available for redistribution

Submit your manuscript at www.biomedcentral.com/submit 